\title{
Wear-resistant nickel-based laser clad coatings for high-temperature applications
}

\author{
A. V. Makarov ${ }^{1,2,3}$, Yu. S. Korobov ${ }^{1,3}$, N. N. Soboleva ${ }^{\dagger, 2,3}$, Yu. V. Khudorozhkova ${ }^{2}$, \\ A. A. Vopneruk ${ }^{4}$, P. Balu 5 , M.M. Barbosa ${ }^{6}$, I. Yu. Malygina' ${ }^{2}$ S. V. Burov' ${ }^{2}$ A. K. Stepchenkov ${ }^{1,2,3}$ \\ †natashasoboleva@list.ru
}

${ }^{1}$ M. N. Miheev Institute of Metal Physics UB RAS, 18 S. Kovalevskaya St., Yekaterinburg, 620108, Russia

${ }^{2}$ Institute of Engineering Science, UB RAS, 34 Komsomolskaya St., Yekaterinburg, 620049, Russia

${ }^{3}$ Ural Federal University n. a. the first President of Russia B. N. Yeltsin, 19 Mira St., Yekaterinburg, 620002, Russia

${ }^{4}$ R\&D Enterprise Mashprom, JSC, 5 Krasnoznamennaya St., Yekaterinburg, 620012, Russia

${ }^{5}$ COHERENT (Deutschland) GmbH, Dieburg, 64807, Germany

${ }^{6}$ Frauhofer IWS, 28 Winterberg St., Dresden, 01277, Germany

\begin{abstract}
The effect of high-temperature processing on laser clad Ni-based coatings is studied. Annealing at $1025^{\circ} \mathrm{C}$ forms thermally stable framework structures with large chromium carbides and borides. As a result, improved hardness and wear resistance of the coating are maintained when heated to $1000^{\circ} \mathrm{C}$. Stabilizing annealing also increases the frictional thermal resistance of the NiCrBSi coating. Under high-speed $(3.1-9.3 \mathrm{~m} / \mathrm{s})$ sliding friction, when the surface layer temperature reaches about $500-1000^{\circ} \mathrm{C}$ and higher, the wear resistance of the coating increases by $1.7-3.0$ times. The proposed approach to the formation of heat-resistant coatings is promising, in particular, for a hot deformation tool and other components of metallurgical equipment operating under high thermal and mechanical loads. Such products include crystallizer walls of continuous casting machines. For the walls, the development of laser cladding technology for wear-resistant composite coatings on copper alloys is relevant as an alternative to thermal spraying. The cladding of composite NiBSi-WC coatings of 0.6 and $1.6 \mathrm{~mm}$ thickness on a Cu-Cr-Zr bronze substrate heated to $200-250^{\circ} \mathrm{C}$ with a diode laser is considered. The presence of boron causes the formation of the $\mathrm{W}(\mathrm{C}, \mathrm{B})$ carboboride phase, whose hardness is higher than that of $\mathrm{WC}$ in the initial powder. Depending on the thickness of coatings and, accordingly, on the duration of heating and the subsequent cooling, the process of secondary carboborides precipitation from the solid solution can be suppressed (in the "thin" coating) or activated (in the "thick" coating). This leads to a higher wear resistance under friction sliding $1.6 \mathrm{~mm}$ thickness coating.
\end{abstract}

Keywords: laser cladding, $\mathrm{NiCrBSi} / \mathrm{NiBSi}-\mathrm{WC}$ coatings, $\mathrm{Cu}-\mathrm{Cr}-\mathrm{Zr}$ substrate, annealing, wear resistance.

\section{Introduction}

Wear- and corrosion resistant nickel-based coatings are widely used for improving the operability of equipment used at high temperatures such as stamping and pressing tools for different types of hot plastic metal forming processes (pressing forming, drawing, forging etc.) [1]. There is an opinion that the degradation of NiCrBSi coatings at temperatures above $700^{\circ} \mathrm{C}$ limits their high-temperature application, since increasing the heating temperature to $700-800^{\circ} \mathrm{C}$ causes a significant hardness and wear resistance decrease of NiCr-based coatings deposited by laser cladding and plasma spraying [2]. Heating up to $800-1100^{\circ} \mathrm{C}$ causes continuous softening of the NiCrBSi coatings deposited by plasma transferred arc welding (PTAW) [3]. In this regard, the investigation aimed at enhancing the thermal stability of the structure and properties of coatings under external and frictional heating is an important task.

In order to increase the wear resistance at high temperatures, Ni-based alloys are strengthened with tungsten carbides phases [4]. The hardness of WC is quite stable as compared to other carbides when temperature increases up to $1300 \mathrm{~K}$ [5]. However, tungsten carbides can partially dissolve in the molten metal pool, even with its small volume and existence time, which is typical for laser cladding [6]. As a result, it leads to a decrease in the content of the strengthening phase in coatings and in the wear resistance [7].

Nickel-based composite coatings are efficiently used on mold copper plates for continuous casting machines (CCM) made of different copper alloys [8,9], which during operation are subjected to intense thermal and mechanical loads, wear and corrosion. In comparison with the industrial thermal spraying of wear-resistant coatings $[8,9]$, laser cladding on mold copper plates should provide better coating adhesion to the substrate and lower coating porosity, advanced process productivity (for example, in the case of line beam cladding with diode lasers). Also, deposition efficiency $(\mathrm{DE})$ of laser cladding $(\mathrm{DE}=95 \%)$ is significantly higher as compared to thermal spraying ( $\mathrm{DE}=40-60 \%)$. Taking into account that the share of the price of powder in the total cost of the coating is about $50-70 \%$, it will give a significant cost efficiency. 
The purpose of this work is to study the performance of combined laser/heat treatment to fabrication the $\mathrm{NiCrBSi}$ coatings with advanced levels of hardness and wear resistance under heating up to $1000^{\circ} \mathrm{C}$ and significant heat release during high-speed friction, as well as to investigate the features of NiBSi-WC composite coatings deposition by a diode laser cladding on $\mathrm{CuCrZr}$ substrate.

\section{Materials and Experimental procedure}

NiCrBSi powder (chemical composition, wt.\% is $16.0 \mathrm{Cr}$; $3.5 \mathrm{~B} ; 4.0 \mathrm{Si} ; 0.80 \mathrm{C}$; $\leq 5 \mathrm{Fe}$; the rest is $\mathrm{Ni}$ ) was used for cladding on a steel substrate in two passes. $\mathrm{CO}_{2}$ continuous wave laser was used with the following parameters: wavelength $10.6 \mu \mathrm{m}$, power $1.4-1.6 \mathrm{~kW}$, scanning speed $160-180 \mathrm{~mm} / \mathrm{min}$, laser beam shape $6.0 \times 1.5 \mathrm{~mm}$, powder feeding rate $2.9-4.9 \mathrm{~g} / \mathrm{min}$, carrier gas argon. The cladded samples were post treated by heating up in a range of $200-1050^{\circ} \mathrm{C}$ with subsequent cooling in air and in vacuum furnace.

Coupons from the Cu-Cr-Zr alloy C18150 ASTM (size $100 \times 100 \times 40 \mathrm{~mm}$ ) were used as substrates for NiBSi-WC coating fabrication. Laser cladding was applied by diode laser HighLight 10000D (Coherent, USA), laser power of $5 \mathrm{~kW}$, wave length of $976 \mathrm{~nm}$, laser beam shape $6 \times 2 \mathrm{~mm}$, scanning pitch $6 \mathrm{~mm}$ and powder feeding rate $36 \mathrm{~g} / \mathrm{min}$. Before laser cladding, the substrates were pre-heated up to $200-250^{\circ} \mathrm{C}$. The coating of $0.6 \mathrm{~mm}$ thickness ("thin" coating) was performed with scanning speed of $10 \mathrm{~mm} / \mathrm{s}$, surface scanning speed of $72 \mathrm{~cm}^{2} / \mathrm{s}$. The coating of $1.6 \mathrm{~mm}$ thickness ("thick" coating) was performed with scanning speed of $2.5 \mathrm{~mm} / \mathrm{s}$, surface scanning speed of $18 \mathrm{~cm}^{2} / \mathrm{s}$. The NiBSi-WC mix of commercial 40\% Hoganas 1559 and $60 \%$ Hoganas 4570 powders with particle size of $53-150 \mu \mathrm{m}$ was used as a feedstock.

The coating microstructure and phase composition were examined by scanning electronic microscopy (SEM) using a Tescan VEGA II XMU microscope, equipped with wave dispersive (Inca Wave 700) and energy dispersive (INCA Energy 450 XT) microanalyzers and a Shimadzu XRD-7000 $\mathrm{X}$-ray diffractometer. Microhardness was evaluated by a HMV-G21 SHIMADZU hardness tester.

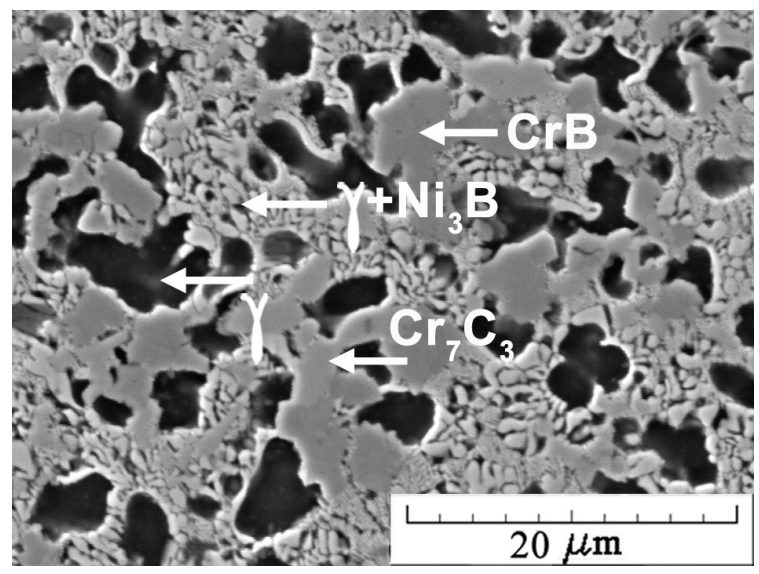

a
The samples with NiCrBSi coating were subjected to a two-body abrasive test over the fixed $\mathrm{Al}_{2} \mathrm{O}_{3}$ corundum abrasive with a specific load $p=1 \mathrm{MPa}$ and average sliding speed $V=0.175 \mathrm{~m} / \mathrm{s}$. The tribological tests of the samples with NiCrBSi coatings were performed according to "pin-ondisk" scheme by sliding the coating surface over the Kh12M steel disk (wt.\%: 1.5C-12Cr-0.5Mo-0.2V; hardness 61.5 HRC) with $p=2 \mathrm{MPa}, V=3.1,4.7,6.1$ and $9.3 \mathrm{~m} / \mathrm{s}$, testing time $t=9.5-30 \mathrm{~min}$. The wear intensity was calculated by the method described in [10]. The tribological tests of NiBSi-WC coating were performed according to "pin-on-plate" scheme by reciprocation sliding the coating surface over the Kh12M steel plate with $p=6 \mathrm{MPa}, V=0.08 \mathrm{~m} / \mathrm{s}$, sliding distance $L=60 \mathrm{~mm}$. Specific wear was determined as the ratio of the mass loss of the sample to $L$. Friction surfaces were studied by SEM.

\section{Results and Discussion}

3.1. Fabrication of heat-resistant NiCrBSi coatings by combined laser-heat treatment (laser cladding + annealing)

The clad coating NiCrBSi over its entire thickness $(1.4-1.5 \mathrm{~mm}$ after grinding) displays a fairly uniform distribution of structural components, as well as approximately constant levels of microhardness and abrasive wear resistance $[11,12]$.

The structure of the coating (Fig. 1a) consists of $\gamma$-Ni solid solution (microhardness 400-450 HV0.05), eutectic $\gamma+\mathrm{Ni}_{3} \mathrm{~B}(580-750 \mathrm{HV} 0.05)$ and main strengthening phases, i.e. chromium carbides $\mathrm{Cr}_{7} \mathrm{C}_{3}(1650-1800 \mathrm{HV} 0.05)$ and chromium borides CrB (1950 - 2400 HV0.05) [13].

The mechanical properties of laser cladding coatings are largely determined by the possible development of secondary phase transformations in the solid state $[14,15]$. A new effect of an increase in the strength and tribological properties of NiCrBSi laser coatings during additional annealing at temperatures of $1000-1075^{\circ} \mathrm{C}$ was found in studies $[13,16]$.

By rapid heating and following rapid solidification of the melt during laser cladding nonequilibrium structures are formed that provide not only advanced properties [17], but also the active development of phase transformations

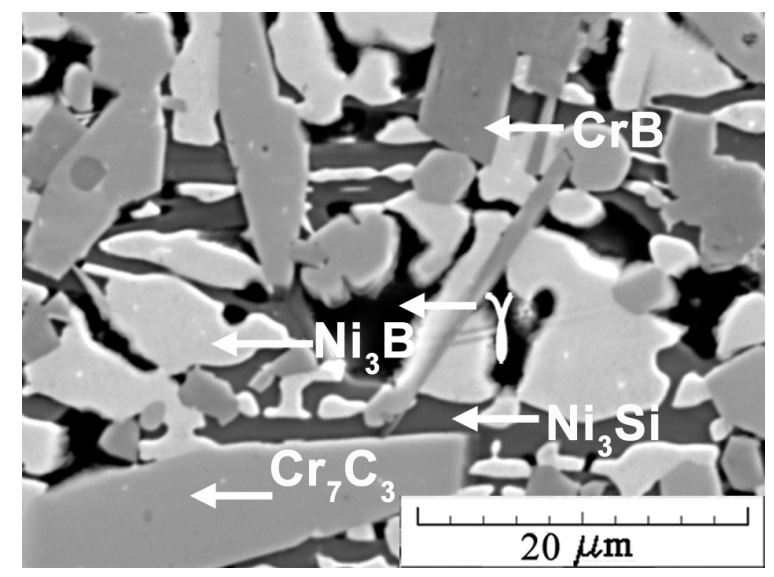

b

Fig. 1. The NiCrBSi coatings microstructure processed by laser cladding (a) and combined laser-heat treatment (laser cladding annealing at $1025^{\circ} \mathrm{C}$ with following furnace cooling) (b). 
associated with dissolution and precipitation during heating and subsequent cooling [18]. High temperature heating $\left(\geq 1000^{\circ} \mathrm{C}\right)$ causes diffusion dissolution of $\mathrm{Ni}_{3} \mathrm{~B}$ particles. Subsequent cooling from the annealing temperature leads to the precipitation of nickel borides and silicides with microhardness of more than $1000 \mathrm{HV}$ and consolidation of the hardest strengthening phases $\mathrm{CrB}$ and $\mathrm{Cr}_{7} \mathrm{C}_{3}$ (1650-2400 HV) forming the wear-resistant structures of a framework type [18]. With a decrease of the cooling rate (for example, from ambient air cooling to vacuum furnace cooling), larger particles of the strengthening phases form (Fig. 1b), that leads to an enhancement of the hardness and wear resistance of the coatings $[13,18]$.

Fig. 2 (curves 1 ) shows that heating up to $900-950^{\circ} \mathrm{C}$ leads to a decrease in the quantity of strengthening phases [17]. It causes a decrease in hardness from 870 to 470 HV0.05 resulting in intense softening of the NiCrBSi coating. It is accompanied by a sharp increase in the abrasive wear intensity from $I_{h}=5.9 \cdot 10^{-6}$ to $I_{h}=(18.6-19.5) \cdot 10^{-6}$.

According to Fig. 2 (curves 2), the coating formed by combined processing (laser cladding + annealing at $1025^{\circ} \mathrm{C}$ ) possesses a high thermal stability after holding at $800-1025^{\circ} \mathrm{C}$ : high microhardness (830-1030 HV0.05) and low wear intensity $I_{h}=(3.3-5.1) \cdot 10^{-6}$ are preserved. Therefore, the combined laser-heat treatment prevents sharp softening and an increase in the abrasive wear intensity upon heating to $900-950^{\circ} \mathrm{C}$ typical for coatings without annealing treatment (curves 1). After reheating up to $1000^{\circ} \mathrm{C}$ and subsequent cooling, coatings formed by combined laser-heat treatment tend to increase their hardness and reduce the wear intensity (curves 2). This indicates a further increase of enlargement of the strengthening phases during repeated heat treatment, similar to their enlargement at a decrease of the cooling rate below annealing temperature (Fig. 1b). Large heat-resistant carbides and borides not only efficiently strengthen the coating, but also form a wear-resistant framework at the sliding surface, which plays the key role in abrasive wear resistance of NiCrBSi coating [19].

The data in the Table 1 show that annealing of NiCrBSi coating provides 1.7-3.0 times lower intensity of the wear by friction in a wide range of sliding speed $(V=3.1-9.3 \mathrm{~m} / \mathrm{s})$ and surface temperature up to about $500-1000^{\circ} \mathrm{C}$.

The revealed effect of the strengthening of coatings by annealing is not observed on Ni-based coatings formed by plasma/flame spraying [20,21] and PTAW [3], which just soften under heating. Laser cladding provides much higher melting and solidification rates. It leads to liquid layering and formation in laser cladding coating of supersaturated nonequilibrium states $[22-24]$, in which processes of dissolution/precipitation of strengthening phases can actively occur during heating.

Suggested new approach opens up unique opportunities for expanding the high-temperature application range of $\mathrm{NiCrBSi}$ alloys in resource-saving technologies for repair as well as for the new equipment production operated in high thermal conditions (metallurgy, heat and electrical equipment, hot plastic metal forming processes, etc.). However, the application of stabilizing annealing is most effective for technologies that form the metastable structures in coatings that are prone to active transformations during

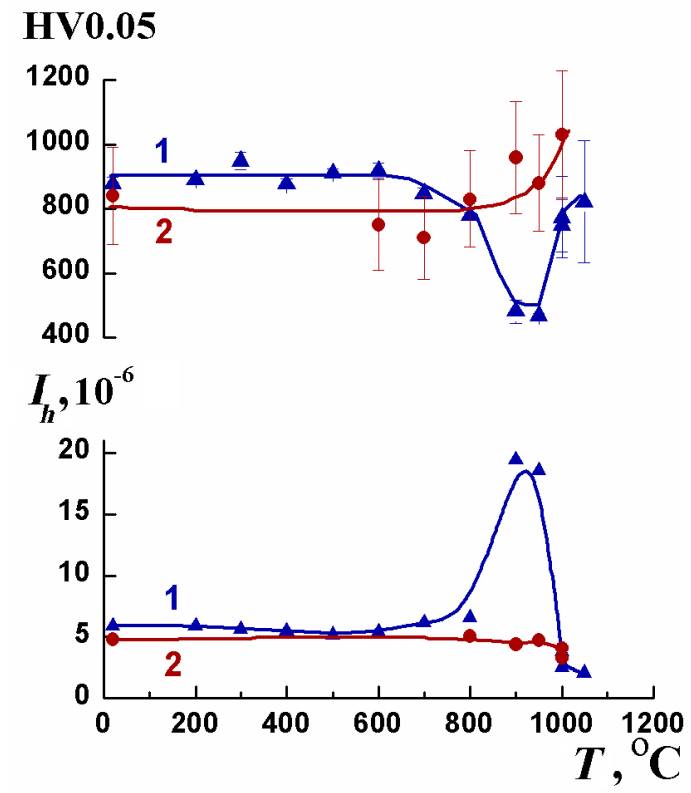

Fig. 2. (Color online) The influence of the heating temperature $T$ (annealing time $1 \mathrm{~h}$ ) on the microhardness HV0.05 and the wear intensity $I_{h}$ by sliding test with corundum for NiCrBSi coatings formed by laser cladding (1) and combined processing: laser cladding + annealing at $1025^{\circ} \mathrm{C}$, air cooling (2).

Table 1. Wear intensity $\left(I_{h}\right)$ and average surface temperature $\left(T_{s}\right)$ of the samples with NiCrBSi coating formed by laser cladding (left) and combined processing (right) under tribological test at various sliding speed $(V)$ and sliding time $(t)$.

\begin{tabular}{|c|c|c|c|}
\hline$V, \mathrm{~m} / \mathrm{s}$ & $t, \min$ & $I_{h}, 10^{-8}$ & $T_{s},{ }^{\circ} \mathrm{C}$ \\
\hline 3.1 & 30 & $4.70 / 1.57$ & $580 / 490$ \\
\hline 4.7 & 30 & $8.78 / 5.13$ & $890 / 840$ \\
\hline 6.1 & 22 & $8.30 / 4.54$ & $920 / 890$ \\
\hline 9.3 & 9.5 & $12.74 / 6.94$ & $>1000$ \\
\hline
\end{tabular}

heat treatment [18]. This concerns not only the laser cladding [11-13,16,18], but also the technology of thermal spraying of composite Ni-based coatings on mold copper plates for CCM $[8,9]$, when ultrahigh solidification rates of sprayed disperse particles is occurring due to intense heat transfer to the copper alloy.

Thus, a new approach to increasing heat resistance (under external and frictional effects) is promising for forming composite coatings on the mold copper plates for CCM made by dispersion hardening copper alloys during two-stage heat treatment $[8,9]$.

As noted in the introduction, the laser cladding technology of composite Ni-based coatings on copper alloys, especially using diode lasers, which allows for high-performance line beam, has an important advantage over the series-applied technology of thermal spraying.

\subsection{Aspects of laser cladding by a diode laser of $\mathrm{NiBSi}$-WC composite coatings on $\mathrm{CuCrZr}$ substrate}

In laser cladding of nickel-based coatings on steel substrate the carbides dissolve in the molten metal pool that leads to a decrease in the hardness of coatings [7]. For copper 
substrate, the existence time of molten metal is much shorter due to 5 times higher thermal conductivity of copper. In our study, the thickness of the deposited layer was taken as an additional factor of influence on this time. The structural features of laser cladding of NiBSi-WC coating on copper substrate with different molten metal existence time are visible in (Fig. 3) applying to "thin" and "thick" coatings.

The structure of the "thin" coating (Fig. 3 a) contains large carbide particles up to $140 \mu \mathrm{m}$ (arrow 1) surrounded by a thin boundary (arrow 2) located in metal matrix with specific grey and light areas (arrows 3, 4). The structure of the "thick" coating (Fig. $3 \mathrm{~b}$ ) also includes large carbide particles up to $140 \mu \mathrm{m}$ (arrow 1) which is surrounded by a wider boundary (width $10-25 \mu \mathrm{m}$, arrow 2), as well as small particles of $10-20 \mu \mathrm{m}$ in size (arrow 5).

$\mathrm{X}$-ray spectrometry microanalysis showed that large particles in both coatings (Fig. 3, arrow 1) consist of about 95 wt.\% tungsten, carbon and boron of $1.12-1.36$ wt.\%. This corresponds to the formation of $\mathrm{W}(\mathrm{C}, \mathrm{B})$ carboborides as a result of primary WC carbides reaction with boron during NiBSi powder melting at laser cladding. The formation of large carboboride particles leads to an increase in the microhardness coating up to $(2680-2700) \pm 130 \mathrm{HV}$ in comparison to the microhardness of primary carbides in initial WC powder $(2200 \mathrm{HV})$. These values correspond to $90 \%$ of the cast tungsten carbide WC microhardness [25] and twice exceed the microhardness of carbides in HVOF coatings.

In the peripheral region of large carboboride particles (indicated by arrow 2 in Fig. 3), due to contact melting and dissolution of the carboboride particle, the tungsten concentration decreases and the Ni content increases (to 5.3 and 15.9 wt.\%, respectively, in the "thin" and "thick" coatings).

The processes mentioned above are significantly inhibited in "thin" coating due to shorter heating time. In "thick" coating the wide peripheral region (the "boundary" indicated by arrow 2 in Fig. 3 b) formed, due to longer existence time of the molten metal pool. In this zone, disperse (up to $10-20 \mu \mathrm{m}$ in size) secondary carboborides $\mathrm{W}(\mathrm{C}, \mathrm{B})$ are precipitated from a NiBSi-based solid solution which is supersaturated

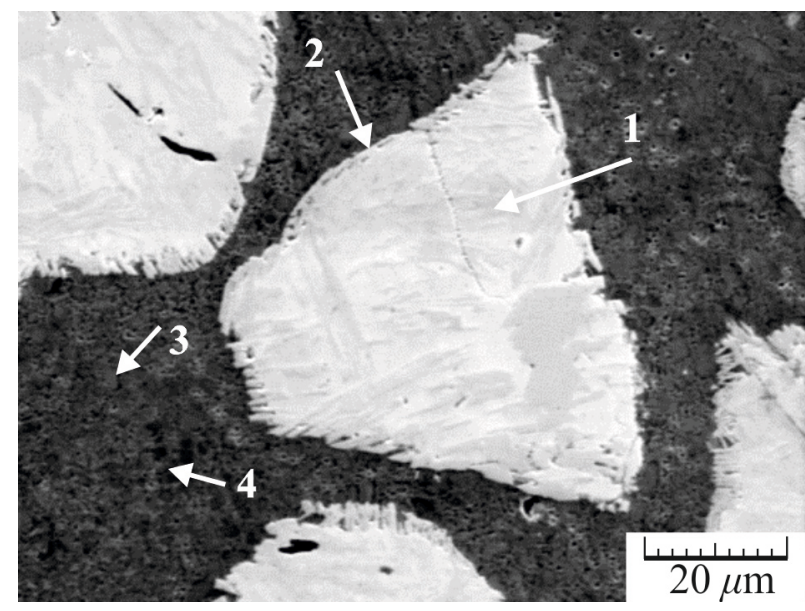

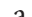

with the products of dissolution of primary tungsten carbides. The microhardness of mentioned peripheral areas $(1260-1870 \mathrm{HV})$ is significantly lower than that of primary large carboboride. In comparison to the "thin" coating (Fig. 3 a), secondary W(C, B) carboborides in "thick" coating are precipitated from supersaturated solid solution not only on the boundaries, but also in the matrix (arrow 5, Fig. 3 b). Such particles can reach microhardness $2425 \mathrm{HV}$ and contain boron about $1.36 \mathrm{wt} . \%$. In the "thin" coating the precipitation of secondary carboborides is limited by higher cooling rate.

The dendritic structure of the "thick" coating is defined in metal matrix (Fig. 3 b) while the "thin" coating microstructure is significantly finer (Fig. 3 a). In the "thick" coating, dendrites (indicated by arrow 3 in Fig. 3 b) are characterized by a lower boron content (1.0 wt.\%) and lower hardness (210 HV). On the contrary, the dark areas are harder (635 HV) (indicated by arrow 4 in Fig. 3 b) due to enrichment with boron (6.55 wt.\%) in comparison with the composition of the initial NiBSi powder (2.9 wt.\% boron).

Due to the strengthening of the matrix by disperse tungsten secondary carboborides, the average hardness of the regions between the large primary particles $\mathrm{W}(\mathrm{C}, \mathrm{B})$ in the "thick" coating increases up to $900 \mathrm{HV}$. In the "thin" coating, disperse light and dark areas of the matrix (indicated by arrows 3 and 4 in Fig. 3 a) have similar levels of boron concentrations (5.9-6.1 wt.\%) and microhardness $(665-690 \mathrm{HV})$. The absence of the secondary carboborides in the matrix of the "thin" coating does not provide its additional strengthening.

Under tribological tests according to the "pin-on-plate" scheme, the "thick" coating showed 20\% lower specific wear $(2.7 \mathrm{mg} / \mathrm{m})$ in comparison with the "thin" coating (3.3 $\mathrm{mg} / \mathrm{m})$. Sliding surfaces investigation showed lower adhesion wear intensity of the matrix of the "thick" coating due to matrix strengthening (up to $900 \mathrm{HV}$ ) by secondary carbides. Moreover, the "thick" coating showed less chipping of the hard $(2680 \mathrm{HV})$ large primary particles $\mathrm{W}(\mathrm{C}, \mathrm{B})$, since they are surrounded by an extended peripheral boundary of secondary tungsten carboborides with an intermediate hardness of $1260-1870 \mathrm{HV}$.

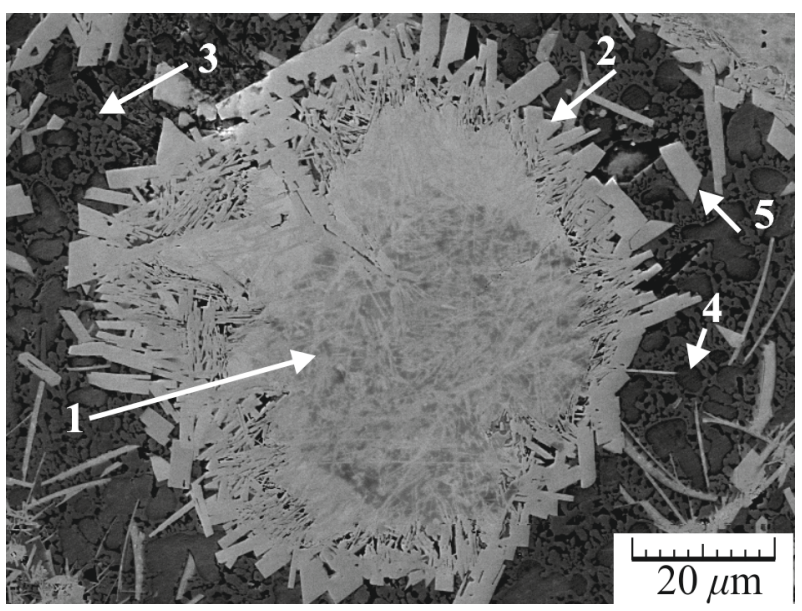

b

Fig. 3. Microstructure of NiBSi-WC coatings of thickness $0.6 \mathrm{~mm}$ (a) and of $1.6 \mathrm{~mm}$ (b): 1 - internal part of large W(C,B) carboboride; 2 - boundary of carboboride particle W(C,B); 3 - dendrites in metal matrix (light areas); 4 - dark areas in metal matrix; 5 - small secondary $\mathrm{W}(\mathrm{C}, \mathrm{B})$ carboboride. 


\section{Conclusion}

High-temperature $\left(1025^{\circ} \mathrm{C}\right)$ annealing of the laser cladding $\mathrm{NiCrBSi}$ coating forms thermally stable wear-resistant structures of the framework type with large strengthening phases (chromium carbides and borides) that allows keeping the advanced levels of hardness and abrasive wear resistance of the coating when heated up to the temperature of $1000^{\circ} \mathrm{C}$. The coating formed by combined laser-heat treatment also showed 1.7-3.0 times increase in wear resistance under sliding with speeds of $3.1-9.3 \mathrm{~m} / \mathrm{s}$, when heating the surface layer reaches temperatures of $500-1000^{\circ} \mathrm{C}$ and above. Suggested approach will significantly expand the high-temperature applications of Ni-based coatings and, in particular, can be used for deposition of wear resistance composite coatings on CCM mold copper plates. Compared with the thermal spraying technology of depositing coatings on copper substrate, diode laser cladding technology has significant advantages.

The possibilities of forming a composite coating with a thickness of 0.6 and $1.6 \mathrm{~mm}$ by a diode laser cladding $\mathrm{NiBSi}-\mathrm{WC}$ powders on a $\mathrm{Cu}-\mathrm{Cr}-\mathrm{Zr}$ alloy substrate preheated to $200-250^{\circ} \mathrm{C}$ are shown. The reaction of WC carbide with boron in the coating leads to the formation of large (up to $140 \mu \mathrm{m})$ particles of $\mathrm{W}(\mathrm{C}, \mathrm{B})$ carboboride, harder $(2700 \mathrm{HV})$ than primary carbides in the initial powder $(2200 \mathrm{HV})$. The increase of the coating thickness to $1.6 \mathrm{~mm}$ leads to a significant dissolution of WC carbides in molten metal. Subsequent cooling promotes precipitation of the disperse (up to $20 \mu \mathrm{m}$ ) secondary tungsten carboborides from the supersaturated solid solution, whose hardness is lower than that of primary WC carbides. The secondary carboborides form a boundary zones (width up to $25 \mu \mathrm{m}$ ) around large $\mathrm{W}(\mathrm{C}, \mathrm{B})$ particles. This leads to the fixation of carboborides in the NiBSi matrix and prevents their chipping under sliding friction conditions. Along with the factor of strengthening of the metal matrix to $900 \mathrm{HV}$ by secondary $\mathrm{W}(\mathrm{C}, \mathrm{B})$ carboborides, it leads to a $20 \%$ increase in wear resistance of "thick" $(1.6 \mathrm{~mm})$ coating in comparison to a "thin" one.

Acknowledgments. The work was supported by the state orders of IMP UB RAS on the subjects "Laser" and "Structure" №AAAA-A18-118020190116-6 and IES №AAAA-A18-118020790147-4. The study of the evolution of the structure of NiCrBSi coatings during heating was carried out with financial support from the Russian Science Foundation, grant № 19-79-00031. The structural studies were done on the equipment installed at the Plastometriya Collective Use Center of IES UB RAS.

\section{References}

1. C. Navas, R. Colaco, J. De Damborenea, R. Vilar. Surf. Coat. Techn. 200, 6854 (2006). Crossref

2. A. Zikin, M. Antonov, I. Hussainova, L. Katona, A. Gavrilović. Tribol. Int. 68, 45 (2013). Crossref
3. O.I. Shevchenko, V.M. Farber, G.E. Trekin. Izvestia VUZov. Chernaya metallurgiya. 10, 76 (1994). (in Russian)

4. K. Günther, J.P. Bergmann. Materials Letters. 213, 253 (2018). Crossref

5. S. Kurlov, A.I. Gusev. Inorganic Materials. 42 (2), 121 (2006). Crossref

6. S. Zhou, Y. Huang, X. Zeng. Appl. Surf. Sci. 254, 3110 (2008). Crossref

7. C. Katsich, E. Badisch. Surf. Coat. Technol. 206, 1062 (2011). Crossref

8. A.V. Kushnarev, A.A. Kirichkov, A.A. Vopneruk, A.B. Kotel'nikov, Yu.S. Korobov, A.V. Makarov, S. V. Filatov, I.N. Shifrin. Svarka i diagnostika. 5, 50 (2017). (in Russian)

9. A.B. Kotel'nikov, A.A. Vopneruk, A.V. Makarov, Yu. S. Korobov, A. A. Kirichkov, A. I. Dagman, I. N. Shifrin. Tyazheloe mashinostroenie. 9, 14 (2018). (in Russian)

10. I. V. Khomskaya, A.E. Kheifets, V.I. Zel'dovich, L. G. Korshunov, N. Yu. Frolova, D. N. Abdullina. Letters on Materials. 8 (4), 410 (2018). Crossref

11. A.V. Makarov, E.S. Gorkunov, I. Yu. Malygina, L. Kh. Kogan, R.A. Savrai, A.L. Osintseva. Russ. J. Nondestr. Test. 45, 797 (2009). Crossref

12. R.A. Savrai, A.V. Makarov, N.N. Soboleva, I. Yu. Malygina, A.L. Osintseva. J. Mater. Eng. Perform. 25 (3), 1068 (2016). Crossref

13. A.V. Makarov, N.N. Soboleva, I. Yu. Malygina, A. L. Osintseva. Met. Sci. Heat Treat. 57 (3-4), 161 (2015). Crossref

14. W.E. Frazier. J. Mater. Eng. Perform. 23 (6), 1917 (2014). Crossref

15. G. Muvvala, D.P. Karmakar, A. K. Nath. Optics Laser Techn. 88, 139 (2017). $\underline{\text { Crossref }}$

16. A.V. Makarov, N.N. Soboleva, I. Yu. Malygina, A. L. Osintseva. RF Patent, BIMP. 26, 2492980 (2013).

17. T. Gómez-del Río, M.A. Garrido, J.E. Fernádez, M. Cadenas, J. Rodríguez. J. Mater. Proces. Technol. 204 (1-3), 304 (2008). Crossref

18. A.V. Makarov, N.N. Soboleva, I. Yu. Malygina, E. V. Kharanzhevskiy. J. Cryst. Growth. 525, 125200 (2019). Crossref

19. A. V. Makarov, N. N. Soboleva, I. Yu. Malygina. J. Frict. Wear. 38 (4), 272 (2017). Crossref

20. H. Skulev, S. Malinov, P. A. M. Basheer, W. Sha. Surf. Coat. Techn. 185 (1), 18 (2004). Crossref

21. Z. Bergant, J. Grum. J. Therm. Spray Technol. 18 (3), 380 (2009). Crossref

22. H. Yan, P. Zhang, Zh. Yu, Q. Lu, Sh. Yang, Ch. Li. Surf. Coat. Techn. 206, 4046 (2012). $\underline{\text { Crossref }}$

23. E. V. Kharanzhevskiy. Phys. Met. Metallogr. 117 (9), 889 (2016). Crossref

24. R. A. Savrai. Phys. Met. Metallogr. 119 (10), 1013 (2018). $\underline{\text { Crossref }}$

25. Refractory Carbides (Ed. by G. V. Samsonov). Springer, USA (1974) $461 \mathrm{p}$. 